\title{
Economic Impacts of Climate Change on Vegetative Agriculture Markets in Israel
}

\author{
Rotem Zelingher ${ }^{1} \cdot$ Andrea Ghermandi $^{2}$ (D) Enrica De Cian ${ }^{3,4} \cdot$ Malcolm Mistry $^{3,4}$. \\ Iddo $\mathrm{Kan}^{1,5}$
}

Accepted: 10 March 2019

(c) Springer Nature B.V. 2019

\begin{abstract}
We integrate the combined agricultural production effects of forecasted changes in $\mathrm{CO}_{2}$, temperature and precipitation into a multi-regional, country-wide partial equilibrium positive mathematical programming model. By conducting a meta-analysis of 2103 experimental observations from 259 agronomic studies we estimate production functions relating yields to $\mathrm{CO}_{2}$ concentration and temperature for 55 crops. We apply the model to simulate climate change in Israel based on 15 agricultural production regions. Downscaled projections for $\mathrm{CO}_{2}$ concentration, temperature and precipitation were derived from three general circulation models and four representative concentration pathways, showing temperature increase and precipitation decline throughout most of the county during the future periods 2041-2060 and 2061-2080. Given the constrained regional freshwater and non-freshwater quotas, farmers will adapt by partial abandonment of agriculture lands, increasing focus on crops grown in controlled environments at the expense of open-field and rain-fed crops. Both agricultural production and prices decline, leading to reduced agricultural revenues; nevertheless, production costs reduce at a larger extent such that farming profits increase. As total consumer surplus also augments, overall social welfare rises. We find that this outcome is reversed if the positive fertilization effects of increased $\mathrm{CO}_{2}$ concentrations are overlooked.
\end{abstract}

Keywords Adaptation - Agriculture $\cdot$ Climate change $\cdot \mathrm{CO}_{2}$ fertilization $\cdot$ Meta-analysis . Positive mathematical programming $\cdot$ Production Function · Israel

Electronic supplementary material The online version of this article (https://doi.org/10.1007/s1064 0-019-00340-z) contains supplementary material, which is available to authorized users.

Iddo Kan

iddo.kan@mail.huji.ac.il

1 Department of Environmental Economics and Management, The Hebrew University of Jerusalem, P.O. Box 12, 761001 Rehovot, Israel

2 Department of Natural Resources and Environmental Management, University of Haifa, 199 Aba Khoushy Ave., Mount Carmel, 3498838 Haifa, Israel

3 Department of Economics, Ca' Foscari University of Venice, 30121 Venice, Italy

4 Centro Euro-Mediterraneo sui Cambiamenti Climatici (CMCC), 30175 Venice, Italy

5 Center for Agricultural Economic Research, The Hebrew University of Jerusalem, P.O. Box 12, 761001 Rehovot, Israel 


\section{Introduction}

Climatic changes are expected to impact agricultural productivity through a series of concomitant factors, which include the rise of near-surface atmospheric carbon dioxide $\left(\mathrm{CO}_{2}\right)$ concentrations, rises in average surface temperatures, changes in temperature extremes, and changes in the geographic distribution and seasonal patterns of precipitations. The extent to which elevated $\mathrm{CO}_{2}$ concentrations affect crops through changes in photosynthesis and stomatal conductance depends on their photosynthetic pathways: while photosynthesis in $\mathrm{C} 3$ crops (e.g., rice, soybeans, wheat) directly and positively responds to increased $\mathrm{CO}_{2}$, giving rise to a " $\mathrm{CO}_{2}$ fertilization effect", $\mathrm{C} 4$ crops (e.g., maize, sorghum) are not directly affected by $\mathrm{CO}_{2}$ levels but may show positive impacts due to increased water use efficiency (Long et al. 2006). Crops' responses to changes in temperature are still highly uncertain (Asseng et al. 2014), but substantial negative impacts are expected especially in hotspot areas where crops already suffer from high temperature stress (Teixeira et al. 2013). Lobell and Field (2007) estimate that changes in average temperatures and precipitation in the growing season alone explain 30\% of the global production of major crops between 1961 and 2002. The extent to which different climate factors interact to impact food production and the resulting economic impacts are still poorly understood (Cai et al. 2016; Rosenzweig et al. 2013).

In the economic literature, common analytical approaches to assess the impacts of climate change on agriculture include the production function approach, Ricardian models, structural models, and General Equilibrium Models (De Salvo et al. 2013; Calzadilla et al. 2013). Programming models implementing a production function approach describe the explicit optimization problem of the farmer and use experimental outputs and regional or farm-level data to calibrate production functions and costs. Under this approach, agricultural profit is maximized as a function of decision-making input variables given the levels of exogenous environmental factors. The impact of forecasted changes in the exogenous environmental factors is elicited by solving the optimization problem under the expected changes. Among the programming models, positive mathematical programming (PMP) models (Howitt 1995) are unique insofar as: (1) they do not require the assumption of having full knowledge of the production process (Schmid and Sinabell 2005); and (2), unlike Ricardian and structural models, they allow to explicitly capture the impact of individual environmental factors on farmers' profit maximizing behavior with respect to land and resources management (Peck et al. 2012). Rosenzweig et al. (2013) first implemented a PMP model to study the combined effect of changes in $\mathrm{CO}_{2}$ concentration, temperature and precipitation on wheat production in semi-arid zones. They conclude that the interactions among climate variables counteract the $\mathrm{CO}_{2}$ fertilization effect resulting in wheat yield decreases by mid-twenty-first century relative to the 1974-2003 baseline period, leading to higher global food price increases than previously anticipated (Easterling et al. 2007).

This study contributes to the economic literature on the impacts of climate change on agriculture by developing and applying a PMP framework to the investigation of the combined impact of climate-change induced modifications in $\mathrm{CO}_{2}$ concentration, temperature and precipitation patterns on an entire vegetative agriculture sector, using the case of Israel. The analysis encompasses the 55 major crops grown in Israel's 15 agricultural production regions. Regional production decisions are interacted through the crops' output prices; the latter constitute equilibria in competitive markets that operate under the presence of import tariffs. First, we develop crop production functions that explicitly incorporate the effect of $\mathrm{CO}_{2}$ concentration, temperature and precipitation, based on the meta-analysis of 2103 
experimental observations from 259 individual agronomic studies. Second, we adopt projections of three General Circulation Models (GCMs) and four representative concentration pathways (RCPs) to simulate climatic conditions in the 15 agricultural regions for the periods 2041-2060 and 2061-2080. Third, we extend the regional PMP model VALUE (Vegetative Agriculture Land Use Economic) (Kan et al. 2009; Palatnik et al. 2011) to explicitly include the effect of $\mathrm{CO}_{2}$ concentration and temperature on agricultural production. ${ }^{1}$ Finally, we implement the extended model to investigate impacts of the forecasted climate change on the vegetative market in Israel in the two future periods, examining changes in land use, output prices, farming revenues, net agricultural profitability, shadow values of land and water constraints, consumer surplus and social welfare.

\section{Methodology and Data}

\subsection{Meta-analysis and Estimation of Production Functions}

Production functions relating changes in climate variables to farming activities play a key role in our climate-change analysis based on the extended VALUE model. To estimate the functions we constructed a database of agronomic experiments exploring the effects of changes in $\mathrm{CO}_{2}$ concentration and temperature on crop yields, encompassing 2103 observations from 259 individual studies published between 1964 and 2016. ${ }^{2}$ Studies from peerreviewed publications as well as grey literature (e.g., reports and theses) were included. In total, the 55 major crops constituting most of the vegetative market in Israel were considered (MOARD-Ministry of Agriculture and Rural Development of Israel). ${ }^{3}$

In order to be included in the database, an experiment in a study had to meet the following criteria:

1. Precise information about the average $\mathrm{CO}_{2}$ concentration and air temperature during the experimental period are provided.

2. Effect on marketable yield is reported.

3. Experimental climate conditions lie within the range of $\mathrm{CO}_{2}$ concentrations and temperatures that characterize Israel's present or future climate. ${ }^{4}$

4. No experimental factor other than $\mathrm{CO}_{2}$ concentration and/or temperature is investigated (e.g., drought, lack or excess of light, toxins, nutrient stress).

\footnotetext{
${ }^{1}$ The effect of precipitation was already included in previous versions of the VALUE model (Kan and Rapaport-Rom 2012). For the present application, we updated precipitation forecasts for the periods under consideration.

${ }^{2}$ We provide here a brief description of the data and meta-analysis; for a complete description see Zelingher (2017).

${ }^{3}$ Due to its dry climate, croplands in Israel are not cultivated specifically as pasturelands for grazing, and livestock feed is mostly based on imported grains and locally produced fodder crops, which are incorporated in the model. Forests, centrally managed by the Jewish National Fund, are typically grown for various ecosystem services on lands with topography and soil quality that are unsuitable for crop production, and are not considered by MOARD as agricultural lands (Dr. Yael Kachel, MOARD, personal communication, July 2018). Thus, our analysis for the case of Israel excludes pasturelands and forestlands; nevertheless, these activities should be considered as substitutes to croplands in economic studies of climate-change agricultural effects in other regions (e.g., in Brazil; Alkimim et al. 2015).

4 "Future climate" refers to the conditions during the periods 2041-2060 and 2061-2080 in Israel as derived from the analysis of the GCMs in Sect. 2.2.
} 
5. In order to exclude outlier observations, the experimental treatment did not result in a yield change greater than $100 \%$ compared to the control.

A sufficient number of observations were available in the database to estimate a specific production function for 20 individual crops. ${ }^{5}$ For the remaining crops, production functions were estimated for crop groups based on hierarchical classifications, first according to botanical families, and then by other agronomic categorization (e.g., grasses, tropical trees). Data regarding the full list of crops, group classification and database descriptive statistics are reported in Appendix A.

The estimated production functions have the following quadratic form, which captures both non-linear effects and potential interactions between $\mathrm{CO}_{2}$ and temperature:

$$
\frac{\Delta y_{b}}{\hat{y}_{b}}=\beta_{1 b} \Delta \mathrm{CO}_{2}+\beta_{2 b} \Delta \mathrm{CO}_{2}^{2}+\beta_{3 b} \Delta T+\beta_{4 b} \Delta T^{2}+\beta_{5 b} \Delta \mathrm{CO}_{2} \Delta T+\varepsilon_{n b}
$$

where $\frac{\Delta y_{b}}{\hat{y}_{b}}$ is the change in the marketable yield relative to the control experiment, $\hat{y}_{b}$, and $\Delta \mathrm{CO}_{2}=\mathrm{CO}_{2}-\widehat{\mathrm{CO}}_{2}$ and $\Delta T=T-\hat{T}$ represent the difference between the temperature and $\mathrm{CO}_{2}$ concentration levels of the treatment group $\left(\mathrm{CO}_{2}, T\right)$ and the control group $\left(\widehat{\mathrm{CO}}_{2}\right.$, $\hat{T})$. The experiment is denoted by $\{n=1, \ldots, 1260\}, b$ is crop type $\{b=1, \ldots, B\}$, and $\varepsilon_{n b}$ is the error term.

Crops in the database are grown under different environmental conditions, as reflected in the different conditions set for the control experiments. The underlying assumption in the choice of the functional form is that a specific crop will respond uniformly across experiments to the same degree of change in the climatic variables. Accordingly, only the experimental changes in the climatic variables are included in the regression, not their initial values. Similarly, other environmental variables (such as soil type and farming practices) that do not change across observations belonging to the same study are excluded. This specification also enables us to estimate the function based on groups of crops in case of insufficient crop-specific experimental observations. The fact that multiple observations from the same experiment are unlikely independent is taken into account by clustering the data based on experiments ${ }^{6}$ and allowing for intra-clusters correlation of the errors (Donoghue 1995). In addition, given that studies report average yield outputs computed based on different numbers of trial repetitions, observations were weighted based on the number of repetitions of the experiment.

The marginal effects of $\mathrm{CO}_{2}$ and $T$ are given by:

$$
\begin{gathered}
M E\left(\mathrm{CO}_{2}\right)=\beta_{1 b}+2 \beta_{2 b} \Delta \mathrm{CO}_{2}+\beta_{5 b} \Delta T \\
M E(T)=\beta_{3 b}+2 \beta_{4 b} \Delta T+\beta_{5 b} \Delta \mathrm{CO}_{2}
\end{gathered}
$$

To account for the randomness of the values of the variables $\Delta \mathrm{CO}_{2}$ and $\Delta T$, which depend on the experimental setup, we employed the bootstrap method with 100 repetitions

\footnotetext{
5 For six crops in the VALUE model (i.e., Other field crops, Other fruits, Other vegetables, Persimmon, Pomegranate, and Sweet potato), we could not retrieve a sufficient number of agronomic experiments to estimate a production function including all three climatic variables under investigation. For these crops, changes in future production were estimated using changes in precipitation only.

6 An "experiment" is thus defined here as a comparison between crops grown under identical conditions with the exception of $\mathrm{CO}_{2}$ and temperature levels.
} 
to calculate the standard deviations associated with the sample-average marginal effects for each crop (or group of crops).

\subsection{Characterization of Future Climate Through GCMs}

Three climatic variables are considered in this study for simulations of future climate conditions: average atmospheric $\mathrm{CO}_{2}$ concentration $\left(\mathrm{CO}_{2 t}\right)$, average surface air temperature $\left(T_{j i t}\right)$, and precipitation during the growing season $\left(w_{j i t}^{r}\right)$, where the index $j$ represents the region out of the 15 regions into which Israel was subdivided, $i(i=1, \ldots, 55)$ represents the crop, and $t$ is the period under consideration. The climatic variables were evaluated with respect to three climate periods: $t=1$ denotes the present conditions, as obtained by averaging the values of the variables over the years $1990-2015 ; t=2$ is the mid-century period, averaging scenario forecasts over the years 2041-2060; $t=3$ is the late twenty-first century, averaging scenario forecasts over the period 2061-2080. We considered all four representative concentration pathways (i.e., RCP2.6, RCP4.6, RCP6.0, RCP8.5) from the IPCC Fifth Assessment Report (IPCC 2014).

Present and future atmospheric $\mathrm{CO}_{2}$ concentrations were retrieved, respectively, from the databases of the National Oceanic Atmospheric Administration (NOAA; http://www. noaa.gov/) and from the RCP Database Version 2.0.5 of the International Institute for Applied Systems Analysis (IIASA; https://tntcat.iiasa.ac.at/RcpDb/). Present levels of monthly precipitations and daily minimum and maximum temperatures were obtained from the Israel Meteorological Service (IMS; http://www.ims.gov.il/IMSENG/All_Tahaz it/homepage.htm). Temperature and precipitation data were available, respectively, in 139 and 487 weather stations throughout the country. For projected temperature and precipitation, we used spatial data at a 30-s resolution from WorldClim-Global Climate Data (http://www.worldclim.org/). ${ }^{7}$ We selected the three GCMs that contain data regarding precipitation, minimum and maximum temperature for all the four RCPs: the Community Climate System Model (CCSM4; Gent et al. 2011); the Model of Interdisciplinary Research on Climate (MIROC5; Watanabe et al. 2010); and the Norwegian Earth System Model (NorESM1-M; Bentsen et al. 2013). ${ }^{8}$ For GCM data, we considered the 258 grid cells that are at least partially within the boundaries of Israel. We calculated the projected temperature and precipitation levels in each of the 15 agricultural regions based on the centroids of each region, which were provided by the MOARD (http://www.moag.gov.il/en), and using inverse distance weighting (IDW) within a radius of $25 \mathrm{~km} .^{9}$

\subsection{Implementation of the VALUE Model}

VALUE (Kan et al. 2009, 2014) is a partial equilibrium, regional scale PMP model that examines adaptation of a vegetative agricultural production sector to changes in various exogenous variables and simulates the optimal allocation of land to crops under competitive

\footnotetext{
7 GCMs were originally designed to simulate the earth's climate. When using downscaled climate data, it is important to recall that the original information was generated at a coarse spatial resolution and did not take into account local topography or land cover patchiness, assuming homogeneity within each grid cell.

8 Therefore, projected temperatures and precipitation assume in our analysis 12 possible values (3 GCMs $\times 4$ RCPs).

${ }^{9}$ Except for the southern Negev region for which a radius of $50 \mathrm{~km}$ was used.
} 
conditions in the vegetative agricultural markets. VALUE assumes profit maximization behavior of farmers with respect to land allocation within each region and uses a calibrated cost function to account for unobserved drivers for the farmers' land diversification across crops. Farmers in all regions face the same statewide output price of each crop, where prices of fresh products allocated to the local markets are determined in equilibrium given world prices and import tariffs, whereas prices of processed food and export markets are exogenous.

VALUE solves the following optimization problem:

$$
\begin{aligned}
& \max _{\mathbf{x}_{t}, \mathbf{m}_{t}} \mathrm{SW}_{t}=\sum_{i=1}^{I}\left(u_{i t}+\sum_{j=1}^{J} x_{j i t}\left(\sum_{k} p_{i}^{k} \mu_{i}^{k} y_{i j t}-\sum_{s a}\left(p^{s a} w_{j i t}^{s a}\right)-\gamma_{j i}-\frac{1}{2} \delta_{j i} x_{j i t}\right)-p_{i t}^{G} m_{i t}\right) \\
& \text { s.t. } \sum_{i=1}^{I} x_{j i t} \leq X_{j} \forall \mathrm{j} \in\{1, \ldots, J\}, \sum_{i=1}^{I} x_{j i t} w_{j i t}^{s a} \leq W_{j}^{s a} \forall s a \in\{1,2\} \& j \in\{1, \ldots, J\}
\end{aligned}
$$

where $\mathbf{x}_{t}$ is the vector of lands allocated to the $I$ crops in the $J$ regions at period $t$, $t=\{1,2,3\}$, with a typical element $x_{j i t}$ as the land allocated to crop $i$ in region $j$ during climate period $t ; \mathbf{m}_{t}$ is the vector of import amounts of the $I$ crops as fresh products; $u_{i t}$ is the country's local consumers total willingness to pay for fresh products of crop $i$ in a year during period $t ; y_{j i t}$ denotes per-dunam output; $\mu_{i}^{k}$ is the fraction of crop-i's total production allocated post harvesting to market $k$ based on quality criteria, with $k=\{e x, p r\}$ representing export and food-processing industry, respectively; $p_{i}^{k}$ is the exogenous price of crop $i$ in market $k ; \sum_{s a}\left(p^{s a} w_{j i}^{s a}\right)$ is the irrigation cost $(s a=1$ and $s a=2$ indicates freshwater and nonfreshwater, respectively). The calibration parameters $\gamma_{j i}$ and $\delta_{j i}$ are derived from the PMP model methodology (Howitt 1995), representing linear diminishing marginal profitability of crops in relation to land. The term $m_{i t}$ represents the imported quantity of crop $i$, where the import price $p_{i t}^{G}$ is exogenous, incorporating the price of the crop-i's fresh product from the cheapest country of source plus import tariffs (Kan et al. 2014). For each crop, prices are assumed to be uniform across the country, as evidenced by official data (IMARD, 2013), and we assume that prices of inputs are fixed over time.

The social welfare objective function, $S W_{t}$, in Eq. (4) is maximized under the following set of constraints: $\sum_{i=1}^{I} x_{j i t} \leq X_{j}$ as a regional land constraint, and $\sum_{i=1}^{I} x_{j i t} w_{j i t}^{s a} \leq W_{j}^{s a} \forall s a=\{1,2\}$ as the freshwater and non-freshwater (i.e., treated wastewater and brackish water) irrigation quotas. The regional constraints $X_{j}, W_{j}^{1}$ and $W_{j}^{2}$ are exogenous, constant over time and untradeable across regions. Farmers are assumed to compensate for reduction in precipitations by additional application of irrigation water, within the constraints of the regional irrigationwater quotas, which remain fixed.

In Eq. (4), the local consumers' willingness to pay for fresh products, $u_{i t}$, is calculated as the integral of the inverse of a constant-elasticity demand function (Fuchs-Rubal 2014):

$$
u_{i t}=\int_{0}^{Y_{i t}} A_{i} \tilde{Y}_{i t}^{\frac{1}{\alpha}} d \tilde{Y}_{i t}=\frac{A_{i} Y_{i t}^{\frac{1}{\alpha}+1}}{\frac{1}{\alpha}+1}
$$

where $Y_{i t}=\sum_{j=1}^{J} \mu_{i}^{l} x_{i j t} y_{i j t}+m_{i t}$ is the nationwide consumption of fresh products associated with crop $i$ during period $t$, which incorporates the import, $m_{i t}$, plus the statewide production allocated to the local fresh-products market, $\sum_{j=1}^{J} \mu_{i}^{l} x_{i j t} y_{i j t}$, with $\mu_{i}^{l}$ indicating the local fresh-market's share in crop-i's total production; $A_{i}$ is a parameter of calibration, and $\alpha$ 
is the demand elasticity. Thus, unlike the prices of exported and processed-food products which are determined in the world markets, the price of crop $i$ in its local fresh-product market, $p_{i}^{l}$, is endogenously determined at equilibrium such that $p_{i}^{l}=A_{i} \mathrm{Y}_{i t}^{\frac{1}{\alpha}} \leq p_{i t}^{G}$. Accordingly, the consumer surplus is $C S_{i}=u_{i}-A_{i} \mathrm{Y}_{i t}^{\frac{1+\alpha}{\alpha}}$.

We introduce the effects of the climatic variables $\mathrm{CO}_{2}$ concentration, temperature and precipitation into VALUE's production functions as follows:

$$
y_{j i t}\left(\mathrm{CO}_{2 t}, T_{j i t}, e_{j i t}\right)=y_{j i 1}\left[1+f\left(\mathrm{CO}_{2 t}, T_{j i t}\right)\right] \times \frac{e_{j i t}}{e_{j i 1}}
$$

where $y_{j i t}$ (ton dunam $^{-1}$ year $^{-1}$ ) is the regional per-dunam ${ }^{10}$ annual yield of crop $i$ at period $t ; y_{j i 1}$ (ton dunam ${ }^{-1}$ year $^{-1}$ ) is the regional yield of crop $i$ during the baseline period; $f\left(\mathrm{CO}_{2 t}, T_{j i t}\right)$ denotes the change in the marketable yield due to changes in $\mathrm{CO}_{2}$ concentration and temperature relative to the baseline period $(t=1)$, as derived from Eq. (1); and $\frac{e_{j i t}}{e_{j i 1}}$ is the yield response to changes in precipitations, water applications and salinity, for which we adopt the function proposed by (Kan et al. 2002):

$$
e_{j i t}\left(W_{j i t}, S_{j i t}\right)=\frac{\bar{e}_{j i}}{1+\alpha_{j i}^{1}\left[\alpha_{j i}^{2} S_{j i}+\alpha_{j i}^{3} W_{j i t}^{\alpha_{j i}^{4}}\right]^{\alpha_{j i}^{5}}}
$$

where $e_{j i t}$ (ft/year) is the evapotranspiration, expressed as a function of water application $W_{j i t}=w_{j i t}^{1}+w_{j i t}^{2}+w_{j i t}^{r}$, and water salinity $S_{j i t}=\sum s^{s a} w_{j i t}^{s a}$, where $s^{1}=1(\mathrm{dS} / \mathrm{m}), s^{2}=2$ $(\mathrm{dS} / \mathrm{m})$, and $s^{r}=0.1(\mathrm{dS} / \mathrm{m})$; the indexes for the water application and salinity parameters refer to, respectively, freshwater irrigation $\left(w_{j i t}^{1}, s^{1}\right)$, non-freshwater irrigation $\left(w_{j i t}^{2}, s^{2}\right)$ and precipitations during crop- $i$ 's growing season $\left(w_{j i t}^{r}, s^{r}\right) ; \bar{e}_{j i}$, and $\alpha_{j i}^{1}$ through $\alpha_{j i}^{5}$ are parameters adopted from Kan and Rapaport-Rom (2012).

To assess the impacts of climate change on vegetative agriculture in Israel, VALUE is implemented in two stages. First, the model is calibrated so that when the levels of the climate variables are set equal to the levels observed during the baseline period, VALUE returns the observed land allocation $\left(x_{j i 1}\right)$ and fresh-product imports $\left(m_{i 1}\right)$. For this study, the baseline year is 2012, for which observed data on costs and land allocation were available from MOARD. Second, climate variables projected by the GCMs for the two investigated future periods are introduced into the production functions of each crop and region, and the model is run so as to produce the associated new decision variables.

\subsection{Climate-Factors Sensitivity Analyses}

In order to examine the effect of each individual climatic factor on the results of the study, we performed a sensitivity analysis using three different versions of the production function $y\left(\mathrm{CO}_{2}, T, e\right)$ in Eq. (6). The first, which we indicate as $y\left(\mathrm{CO}_{2}, T\right)$, in which we omit the index subscripts for simplicity of notation, neglects the effect of changes in precipitations on yields, assuming $\frac{e_{j i t}}{e_{j i 1}}=1$. Therefore, $y\left(\mathrm{CO}_{2}, T, e\right)>y\left(\mathrm{CO}_{2}, T\right)$ would indicate a

10 dunam $=1000 \mathrm{~m}^{2}$. 
positive impact of the projected rainfall changes on yield. The second, $y\left(\mathrm{CO}_{2}, e\right)$, omits the effect of changes in temperature, while the third, $y(T, e)$, neglects the impact of changes in the atmospheric $\mathrm{CO}_{2}$ concentration; these specifications allow us to single out the effect of each climate factor by comparison with the full production function in Eq. (6).

\section{Results}

Table 1 shows the regression coefficients of crop responses to changes in $\mathrm{CO}_{2}$ and temperature as obtained in the linear regression (Eq. 1) and the marginal effects of $\mathrm{CO}_{2}$ and temperature, as well as their statistical significance as obtained through the bootstrapping procedure (Eqs. 2, 3).

As expected, the marginal effect of $\mathrm{CO}_{2}$ increase is positive and significant in most regressions (20 out of 31 ), while the effect of temperature increase differs substantially among crops (or groups of crops), being positive and significant in 8 regressions, and negative and significant in 9 regressions; the latter finding is consistent with previous evidences of the nonlinearity effect of temperature (Schlenker and Roberts 2009). The regression models fit fairly well the observed data, with $R^{2}$ values ranging from 0.25 to 0.83 . The negative signs of the estimated coefficients for the quadratic term of $\mathrm{CO}_{2}$ changes $\left(\beta_{2 b}\right)$ suggest that, while crops benefit from increases in $\mathrm{CO}_{2}$, the effect exhibits diminishing returns to scale.

The analysis of three GCMs and four RCPs indicates that $\mathrm{CO}_{2}$ atmospheric concentration is expected to rise from the present level of about $405 \mathrm{ppm}$ to $443-535 \mathrm{ppm}$ by 2041-2060 and 473-677 ppm by 2061-2080, depending on the concentration pathway under consideration. Mean annual temperatures, averaged over models and regions in Israel, are expected to rise by $1.3-3.1^{\circ} \mathrm{C}$ in $2041-2060$ and $1.8-3.6^{\circ} \mathrm{C}$ in $2061-2080$ compared to the present levels, with the exception of the dry and arid southern Negev region wherein slightly cooler temperatures are expected $\left(-0.8{ }^{\circ} \mathrm{C}\right.$ in $2041-2060 ;-0.2{ }^{\circ} \mathrm{C}$ in 2061-2080). Annual precipitation will decrease in all regions with the exception of the southern Negev, by 12-29\% in 2041-2060 and 20-37\% in 2061-2080. Such results are consistent with the findings of previous climate studies in Israel (Alpert and Silverman 2003; Ben-Gai et al. 1999; Tielbörger et al. 2016). Full details on temperature and precipitation changes for each of the 15 regions are given in Appendix B.

The results of the climate-change simulations using the VALUE model show that all GCM climate models and RCP scenarios predict a reduction in the cultivated agricultural land at the country level (Table 2) (a full breakdown by crops of the projected changes in the agricultural land-use allocation is provided in Appendix C). The extent of the agricultural land use in Israel, which amounts to 2932 thousand dunams in the baseline period, is projected to decrease by $41-48 \%$ by $2061-2080$ even under the most moderate climate change scenario (RCP2.6). Faced with precipitation reductions as predicted by the climate models, farmers choosing to grow crops in open fields will need to use more irrigation water per unit of cultivated area in order to maintain output levels; however, due to the regional water quotas they will be forced to forego some of their currently cultivated lands. Nevertheless, the rising temperature and $\mathrm{CO}_{2}$ concentrations will also affect the per-dunam production, which in turn will change the relative profitability of crops, and thereby the optimal land allocations under the partial-equilibrium output prices. We find that field crops such as hay, rye and oat cultivations will suffer negative effects, and ultimately disappear by 2061-2080. The land allocated to other field crops such as silage and sunflowers will decrease by $94 \%$ in the same period. Cotton fields, on the other hand, will increase by 


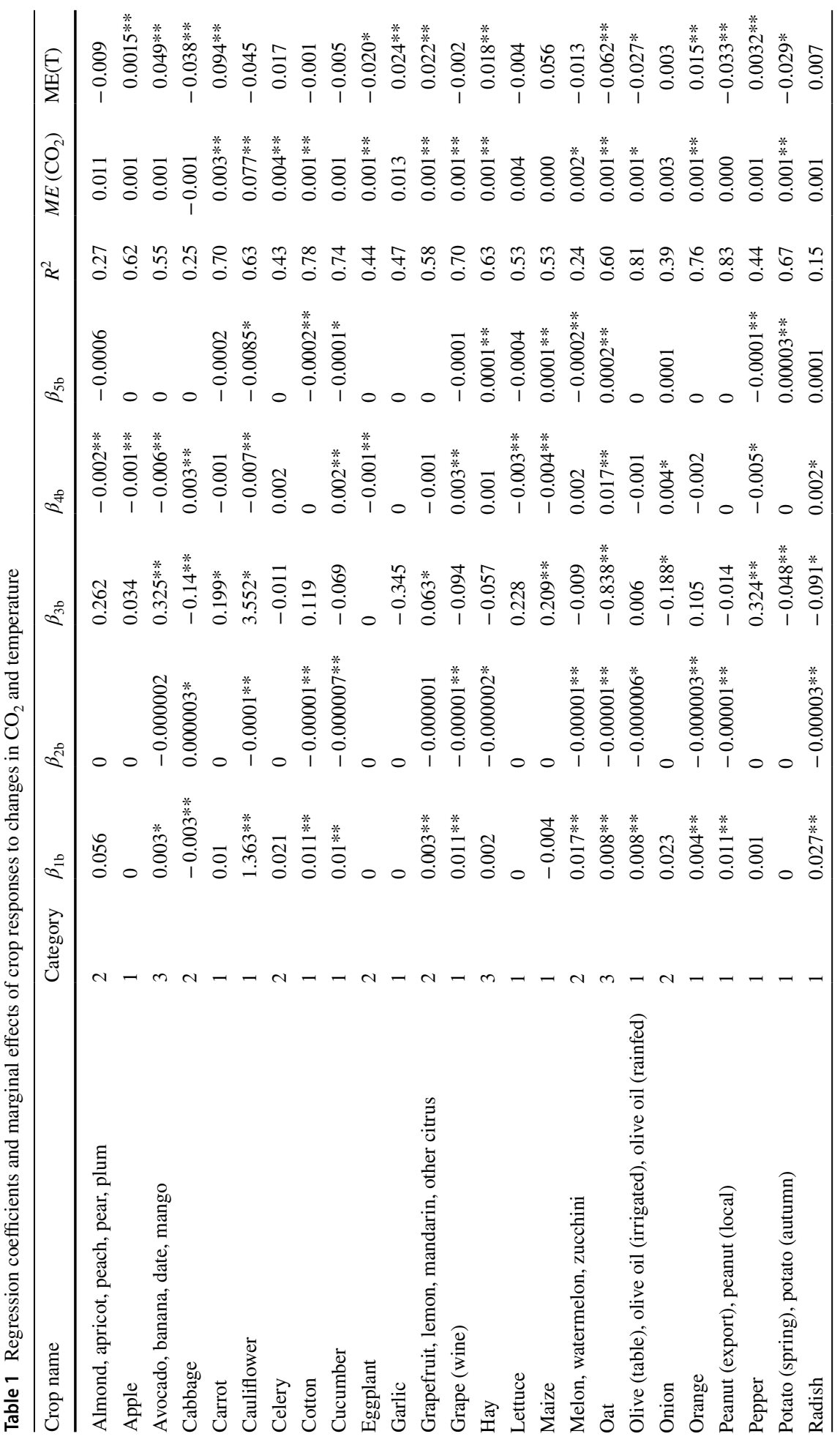




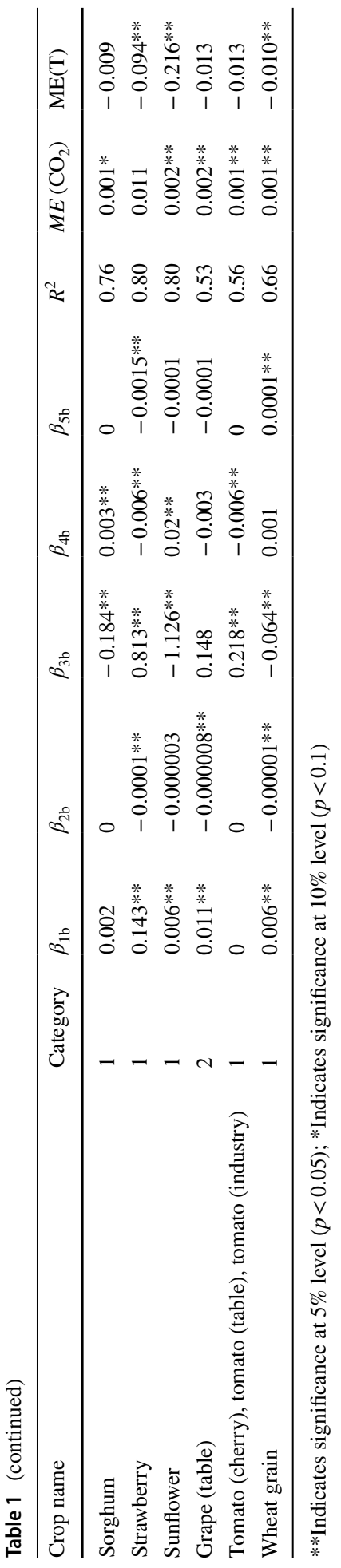


Table 2 Predicted changes in agricultural land use in Israel compared to the baseline period

\begin{tabular}{llllllll}
\hline & \multicolumn{2}{l}{ Period 2041-2060 } & & & \multicolumn{2}{l}{ Period 2061-2080 } \\
\cline { 2 - 3 } & CCSM4 (\%) & MIROC5 (\%) & NorESM1 (\%) & & CCSM4 (\%) & MIROC5 (\%) & NorESM1 (\%) \\
\hline RCP2.6 & -19 & -41 & -14 & -41 & -43 & -48 \\
RCP4.5 & -37 & -36 & -50 & -41 & -50 & -59 \\
RCP6.0 & -40 & -42 & -1 & -48 & -48 & -53 \\
RCP8.5 & -52 & -48 & -47 & -56 & -57 & -61 \\
\hline
\end{tabular}

(a) Changes in Profit per Dunam

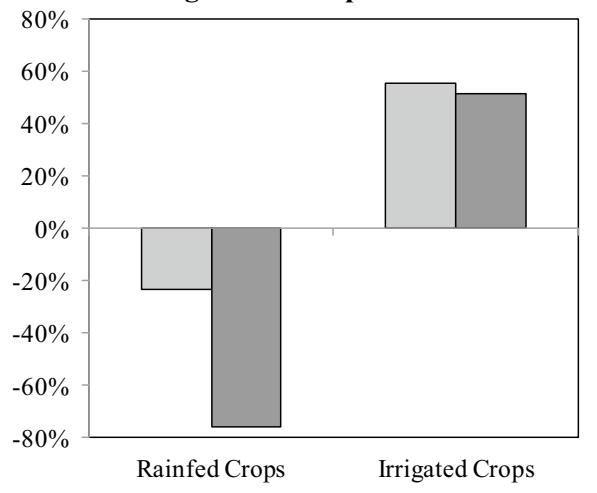

(b)

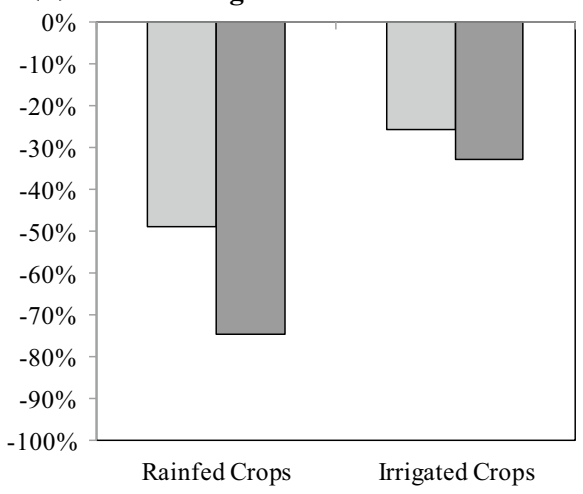

$\square 2041-60 \quad \square 2061-80$

Fig. 1 Changes in a net profitability per dunam and $\mathbf{b}$ agricultural land allocation for rain-fed and irrigated crops

$13 \%$ in area in the two investigated future periods. Land allocation to vegetable cultivation is projected to decrease by $22 \%$ and $26 \%$ in 2041-2060 and 2061-2080, respectively. The area allocated to crops grown in closed facilities such as pepper, cherry tomatoes, and strawberries is expected to slightly increase during the second half of the twenty-first century, compared to today's conditions. Plantations' area is projected to decrease by $37 \%$ in 2061-2080, with a small increase in the land allocated to wine grapes, grapefruit and other citrus. Notably, rain-fed olive oil will almost entirely disappear.

In spite of the projected reduction in the cultivated lands, overall the annual net profits of farmers are expected to grow. Changes in the net profitability of crops show much larger variability than changes in land-use allocation. A full breakdown by crops of the projected changes in net profitability is provided in Appendix C. For rain-fed crops in open fields such as silage, sunflower and rain-fed olive oil, net profitability will be strongly reduced or, in the case of hay, rye and oat, their cultivation will no longer be profitable. On the other hand, crops such as peanuts for domestic consumption, strawberries, potatoes, oranges and plums will experience a strong increase in net profitability per unit area.

A separate analysis for rain-fed and irrigated crops (Fig. 1) helps to clarify the impacts of the aforementioned changes in land allocation and net profitability. The net profit per unit of area is projected to increase for irrigated crops $(+56 \%$ by $2041-2060 ;+51 \%$ by 


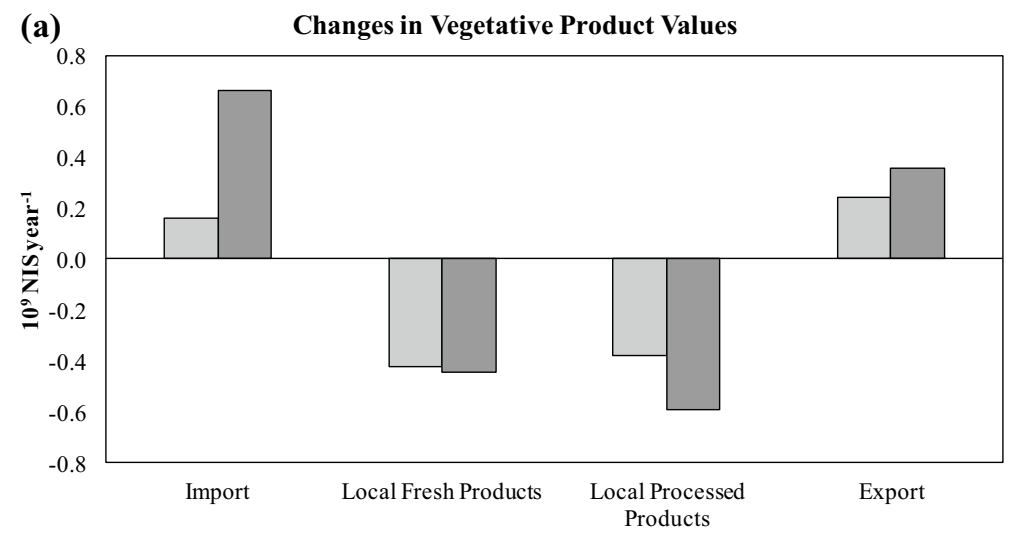

(b) Chanegs in Welfare Factors

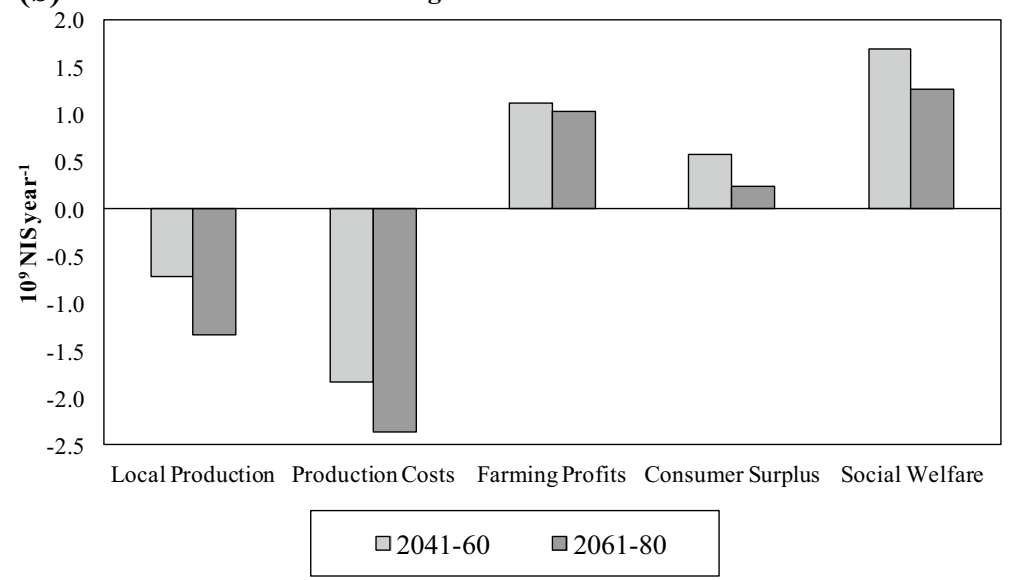

Fig. 2 Statewide values of a import and locally produced fresh, processed and exported products, and $\mathbf{b}$ social welfare factors

2061-2080), whereas the profits of rain-fed agriculture are projected to decrease sharply ( $-24 \%$ by $2041-2060 ;-76 \%$ by $2061-2080$ ). Accordingly, the land allocated to rain-fed crops decreases more steeply than that of irrigated crops.

Figure 2a details the expected changes in the statewide aggregate values of products allocated to various types of markets, averaged over the 12 investigated scenarios. Whereas allocations to the local fresh-product markets and food-processing industry decline, the values of both exported and imported vegetative products rise. The overall annual revenue of the Israeli farmers declines by 0.7 and 1.3 billion NIS a year (Fig. 2b) under the climates forecasted in 2041-2060 and 2061-2080 periods, respectively; that is, reductions of about $4 \%$ and $8 \%$ relative to the total revenue in the base period. This stems from the reduction in both prices and quantities of the vegetative products, as indicated by the computed changes in the Laspeyres price index ( $-3 \%$ and $0 \%$ by $2041-2060$ and $2061-2080$, respectively) and quantity index ( $-2 \%$ by $2041-2060 ;-4 \%$ by $2061-2080)$. Nevertheless, an even larger decline is projected for the statewide production costs (Fig. 2b); hence, the Israeli farming sector eventually benefits from the forecasted climate changes, with a 
Table 3 Regional changes in the use of land and irrigation freshwater and non-freshwater, averaged across 12 scenarios of 4 RCPs and 3 GCM models

\begin{tabular}{|c|c|c|c|c|c|c|}
\hline \multirow[t]{2}{*}{ Region } & \multicolumn{2}{|l|}{ Land } & \multicolumn{2}{|c|}{ Freshwater } & \multicolumn{2}{|c|}{ Non-freshwater } \\
\hline & $\begin{array}{l}2041-2060 \\
(\%)\end{array}$ & $\begin{array}{l}2061-2080 \\
(\%)\end{array}$ & $\begin{array}{l}2041- \\
2060 \\
(\%)\end{array}$ & $\begin{array}{l}2061-2080 \\
(\%)\end{array}$ & $\begin{array}{l}2041-2060 \\
(\%)\end{array}$ & $2061-2080(\%)$ \\
\hline Upper Galilee & -22 & -38 & 0 & -6 & 0 & 0 \\
\hline Golan Heights & -37 & -46 & 0 & 0 & 0 & 0 \\
\hline $\begin{array}{l}\text { Western } \\
\text { Galilee }\end{array}$ & -70 & -78 & 0 & 0 & 0 & 0 \\
\hline Kinneret & -41 & -61 & 0 & 0 & 0 & 0 \\
\hline $\begin{array}{c}\text { Haifa and } \\
\text { Hadera }\end{array}$ & -28 & -41 & 0 & 0 & 0 & 0 \\
\hline $\begin{array}{l}\text { Jordan Rift } \\
\text { Valley }\end{array}$ & -15 & -21 & 0 & 0 & 0 & 0 \\
\hline Jezreel Valley & -35 & -53 & 0 & 0 & 0 & 0 \\
\hline Sharon Plain & -21 & -31 & 0 & 0 & 0 & 0 \\
\hline Petah Tikva & -29 & -42 & 0 & 0 & 0 & 0 \\
\hline $\begin{array}{l}\text { Tel Aviv and } \\
\text { Rehovot }\end{array}$ & -31 & -47 & 0 & 0 & 0 & 0 \\
\hline Ramla & -42 & -53 & 0 & 0 & 0 & 0 \\
\hline Jerusalem & -51 & -60 & 0 & 0 & 0 & 0 \\
\hline Lakhish & -51 & -64 & 0 & 0 & 0 & 0 \\
\hline $\begin{array}{c}\text { Northern } \\
\text { Negev }\end{array}$ & -25 & -38 & 0 & 0 & 0 & 0 \\
\hline $\begin{array}{c}\text { Southern } \\
\text { Negev }\end{array}$ & 0 & 0 & 0 & -5 & -10 & -9 \\
\hline
\end{tabular}

profit change of $+38 \%$ and $+34 \%$ by $2041-2060$ and $2061-2080$, respectively. The total consumer surplus will also augment, leading to an overall social-welfare increase.

The impacts of climate change on Israel's vegetative agriculture will be differentiated regionally. Table 3 reports the changes in regional land and irrigation freshwater and nonfreshwater used for agricultural production, averaged across the 12 scenarios; Table 4 reports the corresponding shadow values of the land and water constraints.

Land allocation to vegetative agriculture will experience a noticeable reduction all over Israel, except for the southern Negev region. The largest reductions are expected in the Western Galilee region. In addition, by 2061-2080 less than half of the current agricultural land use will be cultivated in Lakhish, Kinneret, Jerusalem, Jezreel Valley, and Ramla. The average shadow values of land are projected to decline sharply in most regions, particularly in Lakhish and Western Galilee. The southern Negev, which will experience a slightly cooler and wetter climate, is again an exception. Finally, the average shadow value of irrigation water, both freshwater and non-freshwater, will increase in almost all regions, reflecting the intensified water scarcity.

Figure 3 shows the results of the aforementioned sensitivity analyses with respect to the separate impacts of precipitation, temperature and $\mathrm{CO}_{2}$ concentration, presenting the associated changes in (a) farming profits, (b) consumer surplus and (c) social welfare. The charts show the results of the analyses averaged over the 12 scenarios. 
Table 4 Shadow values of land and irrigation freshwater and non-freshwater by agricultural regions of Israel, averaged across 12 scenarios of 4 RCPs and 3 GCM models

\begin{tabular}{|c|c|c|c|c|c|c|}
\hline \multirow[t]{2}{*}{ Region } & \multicolumn{2}{|c|}{$\begin{array}{l}\text { Land (NIS dunam } \\
\text { year }^{-1} \text { ) }\end{array}$} & \multicolumn{2}{|c|}{ Freshwater (NIS m ${ }^{-3}$ ) } & \multicolumn{2}{|c|}{ Non-freshwater (NIS m ${ }^{-3}$ ) } \\
\hline & 2041-2060 & $2061-2080$ & $2041-2060$ & 2061-2080 & $2041-2060$ & 2061-2080 \\
\hline Upper Galilee & 11.46 & 0.64 & 3.71 & 3.31 & 0.89 & 1.33 \\
\hline Golan Heights & 3.29 & 0.00 & 3.47 & 3.49 & 0.96 & 1.35 \\
\hline Western Galilee & 0.25 & 0.00 & 3.35 & 3.28 & 1.13 & 1.51 \\
\hline Kinneret & 13.96 & 0.00 & 3.02 & 3.33 & 1.03 & 1.38 \\
\hline Haifa and Hadera & 13.33 & 0.00 & 2.72 & 2.66 & 1.03 & 1.45 \\
\hline Jordan Rift Valley & 8.05 & 0.00 & 2.73 & 2.74 & 1.10 & 1.42 \\
\hline Jezreel Valley & 9.07 & 0.00 & 3.02 & 2.86 & 0.80 & 1.14 \\
\hline Sharon Plain & 11.84 & 0.00 & 1.94 & 2.31 & 1.09 & 1.47 \\
\hline Petah Tikva & 8.62 & 0.00 & 2.81 & 2.95 & 0.97 & 1.38 \\
\hline Tel Aviv and Rehovot & 13.16 & 0.00 & 3.12 & 3.29 & 1.15 & 1.57 \\
\hline Ramla & 2.96 & 0.00 & 3.12 & 3.13 & 0.99 & 1.41 \\
\hline Jerusalem & 0.00 & 0.00 & 3.49 & 3.54 & 1.14 & 1.50 \\
\hline Lakhish & 0.03 & 0.00 & 2.75 & 2.78 & 0.90 & 1.31 \\
\hline Northern Negev & 6.11 & 0.00 & 3.05 & 3.36 & 1.06 & 1.63 \\
\hline Southern Negev & 901.56 & 1010.09 & 2.40 & 1.90 & 0.00 & 0.00 \\
\hline
\end{tabular}

In the baseline period, the shadow values of land, freshwater and non-freshwater are, respectively 18.07 (NIS dunam ${ }^{-1}$ year $\left.^{-1}\right), 0.23\left(\mathrm{NIS} \mathrm{m}{ }^{-3}\right)$ and $0.04\left(\mathrm{NIS} \mathrm{m}^{-3}\right)$
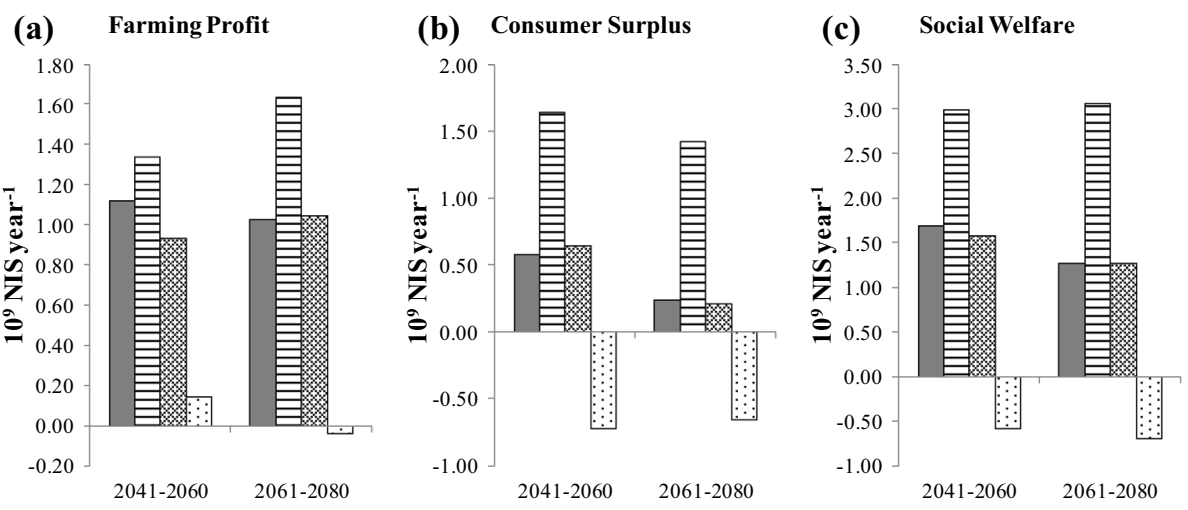

$\square y\left(\mathrm{CO}_{2}, \mathrm{~T}, e\right) \quad \boxminus y\left(\mathrm{CO}_{2}, \mathrm{~T}\right) \quad \otimes y\left(\mathrm{CO}_{2}, e\right) \quad \square y(T, e)$

Fig. 3 Sensitivity analyses of the statewide effects of climate variables over a farming profits, $\mathbf{b}$ consumer surplus and c social welfare

A comparison of the results obtained with the full production function, $y\left(\mathrm{CO}_{2}, T, e\right)$, to those with the function that excludes the impact of precipitation changes, $y\left(\mathrm{CO}_{2}, T\right)$, points at the significant negative effect of the forecasted precipitation reduction on both farming profits and consumer surplus, resulting in a social-welfare loss of 1.3 and 1.8 billion NIS a year in 2041-2060 and 2061-2080, respectively. On the other hand, temperature 
changes play a much smaller role, as indicated by the minor changes in both farming profits and consumer surplus when the production function $y\left(\mathrm{CO}_{2}, T, e\right)$ is replaced by $y\left(\mathrm{CO}_{2}, e\right)$. Finally, changes in $\mathrm{CO}_{2}$ are predicted to have a significant positive impact on social welfare in the Israeli market: by adopting $y(T, e)$ as the production function we obtain an almost no climate-change impact on farming profits, a sharp reduction in consumer surpluses, and an overall welfare loss of 0.6 and 0.7 billion NIS a year in the 2041-2060 and 2061-2080 periods, respectively. Thus, overlooking the fertilization effect of $\mathrm{CO}_{2}$ reverses the projected welfare effects of climate change, which underlines the importance of including this variable in climate-change economic models.

\section{Conclusions}

This study contributes to the literature on the economic impacts of climate change in agriculture by providing the first country-wide application of a PMP model to the entire vegetative agriculture market, which includes the combined effects of changes in $\mathrm{CO}_{2}$, temperature and precipitation on 55 crops in 15 agricultural production regions under competitive partial-equilibrium conditions. Through a meta-analysis of agronomic studies, production functions accounting for the effects of rising $\mathrm{CO}_{2}$ and temperature on marketable crop yields were developed. Downscaled climate change projections for $\mathrm{CO}_{2}$ concentration, temperature and precipitation were derived for three GCMs and four RCPs. Under the assumption of profit-maximization behavior on the part of farmers that operate in competitive markets, our study predicts that Israeli farmers will compensate for the lower amount of precipitation by increasing the amount of irrigation, with the consequences of retiring part of their agricultural land due to irrigation water constraints, and strongly reducing or forfeiting the cultivation of rain-fed crops in open fields. The reliance of Israel on imported vegetative products will consequently increase. Nevertheless, under equilibrium in the markets for agricultural products, these changes benefit both producers and consumers.

While the paper focuses on impacts and adaptation of the agricultural sector to climatic changes, it should be recognized that agriculture is a substantial contributor to greenhouse gas emissions, either directly (e.g., nitrous oxide from fertilized soils, methane emissions from livestock) or indirectly through land conversion (Avetisyan et al. 2014; Smith et al. 2014). The feedback effects of these factors on the climate are not investigated in this study due to the small size of Israel's vegetative agricultural sector in the context of global markets and greenhouse gas emissions; however, the implementation of the proposed methodology at larger scales should account for the endogeneity associated with the atmospheric level of $\mathrm{CO}_{2}$, as well as the climatic effects of other gases with global worming potentials.

Changes of the magnitude described in this paper are likely to be felt beyond the boundaries of the agricultural sector, especially if one considers that the sector is already experiencing the stress imposed by water scarcity and the national land policy (Hananel 2010). Israel's agriculture is not only embedded in its national heritage, but also performs significant ecological and environmental functions, insofar as, for instance, it limits the conversion of open space to built-up areas (Shuval 2013). Beyond the market value of its output, agricultural land has been acknowledged as a source of amenity value (Fleischer and Tsur 2009; Kan et al. 2009), both in the form of non-market benefits through recreation and for its association with rural tourism (Tchetchik et al. 2008). Heritage considerations are among the drivers for preservation of old olive groves and may be associated with substantial non-use values (Loumou and Giourga 2003; Becker and Freeman 2009). The extent 
to which the impacts of climate change identified in this study will affect Israeli society, culture and environment at large remain to be investigated.

Under the assumption of a small economy with agricultural sector protected by import tariffs, constant input prices and fixed and untradeable regional water quotas, we find that social welfare will increase in the future due to an increase in both consumer surplus and farmers' profits. This is consistent with previous findings from Israel (Yehoshua and Shechter 2003; Likhtman 2006; Fleischer et al. 2008) and elsewhere (Solow et al. 1998). Crucially, we find that the "fertilization effect" of $\mathrm{CO}_{2}$ concentration-increase is critical in determining such outcome, whose sign would have been reversed in the absence of such effect.

Further improvement of the analytical framework proposed in this study could include consideration of the effect of additional climate explanatory variables (e.g., relative humidity, wind and radiation) and the initial condition of the climatic variables on the production functions. Moreover, relaxation of the assumptions regarding inter-regional trade of irrigation-water quotas may improve farmers' ability to adapt to climatic changes. International trade patterns may affect the results through changes in prices and climate-induced changes in competitiveness (Calzadilla et al. 2013).

From a policy perspective, our results project increased levels of crop imports, which will strengthen the reliance of Israel's economy on imports of "virtual water" (Kislev 2011). Furthermore, they suggest the importance of exploring how different policies regarding the determination of regional water quotas (e.g., enabling farmers to purchase desalinated water with no quantity constraint would enhance the farmer's control on land and water allocation, but increase water costs), the tradability of production inputs, and taxation would affect farmers' ability to adapt to climate change in Israel.

Acknowledgements Funding was provided by the Center for Agricultural Economic Research, Department of Environmental Economics and Management, The Hebrew University of Jerusalem.

\section{References}

Alkimim A, Sparovek G, Clarke KC (2015) Converting Brazil's pastures to cropland: an alternative way to meet sugarcane demand and to spare forestlands. Appl Geogr 62:75-84

Alpert P, Silverman D (2003) Vulnerability of water resources in eastern Mediterranean ecosystems due to climate change: an integrated approach to sustainable management. Paper presented at American Meteorological Society conference on impacts of water variability: benefits and challenges, Long Beach, CA

Asseng S, Ewert F, Matre P et al (2014) Rising temperatures reduce global wheat production. Nat Clim Chang 5:143-147

Avetisyan M, Hertel T, Sampson G (2014) Is local food more environmentally friendly? The GHG emissions impacts of consuming imported versus domestically produced good. Environ Resour Econ 58:415-462

Becker N, Freeman S (2009) The economic value of old growth trees in Israel. For Policy Econ 11:608-615

Ben-Gai T, Bitan A, Manes A et al (1999) Temporal and spatial trends of temperature patterns in Israel. Theor Appl Climatol 64:163-177

Bentsen M, Nethke I, Debernard JB et al (2013) The Norwegian Earth System Model, NorESM1-M-Part 1: description and basic evaluation of the physical climate. Geosci Model Dev 6:687-720

Cai C, Yin X, He S et al (2016) Responses of wheat and rice to factorial combiations of ambient and elevated $\mathrm{CO}_{2}$ and temperature in FACE experiments. Glob Change Biol 22:856-874

Calzadilla A, Rehdanz K, Betts R et al (2013) Climate change impacts on global agriculture. Clim Change 120:357-374

De Salvo M, Begalli D, Signorello G (2013) Measuring the effect of climate change on agriculture: a literature review of analytical models. J Dev Agric Econ 5:499-509 
Donoghue JR (1995) The effects of within-group covariance structure on recovery in cluster analysis: I. The bivariate case. Multivar Behav Res 30(2):227-254

Easterling WE, Aggarwal PK, Batima P et al (2007) Food, fibre and forest products. In: Parry ML, Canziani OF, Palutikof JP et al (eds) Climate change 2007: impacts, adaptation and vulnerability. Cambridge University Press, Cambridge

Fleischer A, Tsur Y (2009) The amenity value of agricultural landscape and rural-urban land allocation. J Agric Econ 60(1):132-153

Fleischer A, Lichtman I, Mendelsohn R (2008) Climate change, irrigation, and Israeli agriculture: will warming be harmful? Ecol Econ 65:508-515

Fuchs-Rubal H (2014) The effect of reforms in agricultural crop quotas on producers and consumers. Master thesis, The Hebrew University of Jerusalem (in Hebrew)

Gent PR, Danabasoglu G, Donner LJ et al (2011) The community climate system model version 4. J Clim 24:4973-4991

Hananel R (2010) Zionism and agricultural land: national narratives, environmental objectives, and land policy in Israel. Land Use Policy 27:1160-1170

Howitt RE (1995) Positive mathematical programming. Am J Agric Econ 77:329-342

IPCC (2014) Climate change 2014: synthesis report. Intergovernmental Panel on Climate Change (IPCC), Geneva

Israeli Ministry of Agriculture and Rural Development (2013) Wholesale Price Survey. http://www.moag. gov.il/yhidotmisrad/itzur_economy/Overview_Prices/Pages/prices.aspx (in Hebrew). Accessed 19 Dec 2018

Kan I, Rapaport-Rom M (2012) Regional blending of fresh and saline irrigation water: is it efficient? Water Resour Res 48:W07517

Kan I, Schwabe KA, Knapp KC (2002) Microeconomics of irrigation with saline water. J Agric Resour Econ 27(1):16-39

Kan I, Haim D, Rapaport-Rom M et al (2009) Environmental amenities and optimal agricultural land use: the case of Israel. Ecol Econ 68:1893-1898

Kan I, Finkelstein I, Rapaport-Rom M (2014) Simulations of changes in the agricultural trade policy using a computational equilibrium model. Paper presented at Seminar on studies in agricultural economics and rural development. Ministry of Agriculture and Rural Development, Jerusalem (in Hebrew)

Kislev Y (2011) The water economy of Israel. Policy Program Paper, Taub Center for Social Policy Studies in Israel, Jerusalem

Likhtman E (2006) The impact of climate change on the profitability of agricultural farms in Israel. Master thesis, The Hebrew University of Jerusalem (in Hebrew)

Lobell DB, Field CB (2007) Global scale climate-crop yield relationships and the impacts of recent warming. Environ Res Lett 2:1-7

Long SP, Noesberger J, Ainsworth EA et al (2006) Food for thought: lower-than-expected crop yield stimulation with rising $\mathrm{CO}_{2}$ concentrations. Science 312:1918-1921

Loumou C, Giourga C (2003) Olive groves: the life and identify of the Mediterranean. Agric Hum Values 20:87-95

Palatnik RR, Eboli F, Ghermandi A et al (2011) Integration of general and partial equilibrium agricultural land-use transformation for the analysis of climate change in the Mediterranean. Climate Change Econ 2(4):275-299

Peck DE, Adams RM, Dinar A et al (2012) Farm-level impacts of climate change: alternative approaches for modeling uncertainty. In: Dinar A, Mendelsohn RO (eds) Handbook on climate change and agriculture. Edward Elgar Publishing, Cheltenham

Rosenzweig C, Jones JW, Hatfield JL et al (2013) The Agricultural Model Intercomparison and Improvement Project (AgMIP): protocols and pilot studies. Agric For Meteorol 170:166-182

Schlenker W, Roberts MJ (2009) Nonlinear temperature effects indicate severe damages to US crop yields under climate change. Proc Natl Acad Sci 106(37):15594-15598

Schmid E, Sinabell F (2005) Using the positive mathematical programming method to calibrate linear programming models. Discussion Paper, University of Natural Resources and Applied Life Sciences, Vien

Shuval H (2013) The agricultural roots of Israel's water crisis. In: Orenstein DE, Miller C, Tal A (eds) Between ruin and restoration: an environmental history of Israel, University of Pittsburgh Press. Pittsburgh, PA

Smith P, Bustamante M, Ahammad H et al (2014) Agriculture, forestry and other land use (AFOLU). In: Edenhofer O, Pichs-Madruga R, Sokona Y et al (eds) Climate Change 2014: Contribution of Working Group III to the Fifth Assessment Report of the Intergovernmental Panel on Climate Change, Cambridge University Press, Cambridge, UK and New York, NY, USA 
Solow AR, Adams RF, Bryant KJ et al (1998) The value of improved ENSO prediction to U.S. agriculture. Clim Change 39:47-60

Tchetchik A, Fleischer A, Finkelshtain I (2008) Differentiation and synergies in rural tourism: estimation and simulation of the Israeli market. Am J Agric Econ 90(2):553-570

Teixeira EI, Fischer G, van Velthuizen H et al (2013) Global hot-spots of heat stress on agricultural crops due to climate change. Agric For Meteorol 170:206-215

Tielbörger K, Claus C, Schloz D et al (2016) Sustainable water and land management under global change. In: Borchardt D, Bogardi JJ, Ibisch RB (eds) Integrated water resources management: concept, research and implementation. Springer, Cham

Watanabe M, Suzuki T, O'ishi R et al (2010) Improved climate simulation by MIROC5: mean states, variability and climate sensitivity. J Clim 23:6312-6335

Yehoshua N, Shechter M (2003) Climate change and agriculture: an Israeli perspective. In: Giupponi C, Shechter M (eds) Climate change and the Mediterranean: socio-economic perspectives of impacts, vulnerability and adaptation. Edward Elgar, Cheltenham

Zelingher R (2017) Evaluating the economic impact of climate change on vegetative agriculture in Israel. Master thesis, The Hebrew University of Jerusalem

Publisher's Note Springer Nature remains neutral with regard to jurisdictional claims in published maps and institutional affiliations. 